\title{
Rancang Bangun Sistem Informasi Manajemen Pengaduan Masyarakat dan Monitoring Akademik Perguruan Tinggi
}

\author{
Frits Gerit John Rupilele ${ }^{[1]}$, Aram Palilu ${ }^{[2]}$ \\ Program Studi Sistem Informasi Universitas Victory Sorong ${ }^{[1]}$ \\ Program Studi Administrasi Publik Universitas Victory Sorong ${ }^{[2]}$ \\ fritsrupilele@gmail.com ${ }^{[1]}$, arampalilu1015@gmail.com ${ }^{[2]}$
}

\begin{abstract}
Abstrak-Lembaga Layanan Pendidikan Tinggi (LLDIKTI) merupakan satuan kerja pemerintah di wilayah yang berfungsi membantu peningkatan mutu penyelenggaraan Pendidikan Tinggi, baik perguruan tinggi negeri maupun swasta agar dapat menyelenggarakan Pendidikan Tinggi secara akuntable yang sesuai dengan Standar Nasional Pendidikan Tinggi. Salah satu kegiatan LLDIKTI untuk menjaga agar PT tidak jatuh dalam pelanggaran penyelenggaraan pendidikan tinggi adalah melalui kegiatan pengendalian, pengawasan, dan pembinaan (dalwasbin). Kegiatan dalwasbin merupakan kegiatan monitoring kinerja akademik yang dilakukan setiap tahun oleh Tim Evaluasi Kinerja Akademik yang dibentuk oleh LLDIKTI. Kegiatan monitoring dan evaluasi terhadap kinerja akademik PT dilakukan berdasarkan data dan informasi yang berasal dari laporan/pengaduan masyarakat secara lisan/tulisan, hasil pemantauan dan evaluasi, serta pemberitaan melalui media masa. LLDIKTI Wilayah XIV Papua dan Papua Barat saat ini mengalami kesulitan dalam mendapatkan informasi atau keluhan dari masyarakat tentang pelanggaran PT dan juga kesulitan melakukan pemantauan terhadap penyelenggaraan PT karena faktor geografis wilayah PT yang sangat luas dan jaringan transportasi yang sulit maupun terbatas serta tidak adanya sistem untuk menampung dan mengelolah keluhan atau pengaduan masyarakat terkait pelanggaraan-pelanggaran yang dilakukan oleh PT. Perancangan sistem informasi dalam penelitian ini berbasis web yang menggunakan metode waterfall, sedangkan untuk perancangan model sistem manggunakan diagram-diagram unified modeling language. Hasil pengembangan sistem informasi manajemen pengaduan masyarakat dan monitoring kinerja akademik PT adalah LLDIKTI Wilayah XIV memiliki suatu sistem yang menyediakan media pengaduan masyarakat sehingga membantu dalam manajemen pendataan pelanggaran PT dan manajemen kegiatan monitoring kinerja akademik PT yang terintegrasi dan terpusat, serta menghasilkan laporan data pemeriksaan PT yang menjadi masukan dan informasi bagi LLDIKTI dan kementerian dalam pemetaan kualitas kelembagaan Pendidikan tinggi.
\end{abstract}

Kata Kunci : Sistem Informasi, Pengaduan, LLDIKTI, Waterfall.

\section{PENDAHULUAN}

Perguruan Tinggi (PT) merupakan satuan pendidikan yang menyelenggarakan pendidikan tinggi yang mengemban tugas untuk penyelenggaran program pendidikan akademik atau profesional melalui kegitan pendidikan atau pengajaran, penelitian, maupun kegiatan pengabdian kepada masyarakat. PT sebagai bagian integral dalam sistem pendidikan nasional sebagaimana diamanatkan dalam Undang-Undang Nomor 12 Tahun 2012 tentang Pendidikan Tinggi bertujuan mengembangkan ilmu pengetahuan dan teknologi serta menghasilkan manusia intelektual, ilmuan, tenaga professional yang berbudaya dan kreatif, toleran, demokratis, berkarakter, tangguh serta berani membela kebenaran untuk kepentingan bangsa [1]. Penyelengaraan dan pengelolaan PT harus mengacu pada Standar Nasional Pendidikan Tinggi, sebagaimana diatur dalam Permenristekdikti Nomor 44 tahun 2015 tentang Standar Nasional Pendidikan Tinggi (SN DIKTI). Dalam praktik penyelenggaran pendidikan tinggi ditemukan tidak sedikit penyelenggaran PT yang melanggar dan menyimpang dari SN DIKTI.

Pelanggaran pada SN DIKTI akan melahirkan lulusan PT yang jauh dari kompetensi yang diharapkan, baik menyangkut aspek kognitif, afektif, maupun psikomotorik. Upaya untuk menjaga agar PT tidak jatuh dalam pelanggaran penyelenggaraan pendidikan tinggi dapat dilakukan melalui kegiatan pengendalian, pengawasan, dan pembinaan (dalwasbin), baik yang dilakukan oleh Kemenristekdikti melalui Direktorat Jenderal Kelembaggaan Ristek Dikti maupun melalui Lembaga Layanan Dikti/Kopertis di tingkat wilayah [1], [2]

Kopertis Wilayah XIV yang telah berubah status menjadi LLDIKTI Wilayah XIV memiliki wilayah kerja di Provinsi Papua dan Papua Barat. LLDIKTI Wilayah XIV bertugas melaksanakan dan memfasilitasi peningkatan mutu penyelenggaraan pendidikan tinggi di wilayah kerjanya salah satunya melaksanakan dalwasbin terhadap Perguruan Tinggi. Pada tahun 2017, berdasarkan hasil monitoring dan evaluasi penyelenggaraan PT yang dilakukan oleh Tim Evaluasi Kinerja Akademik (Tim EKA), menemukan sebanyak 29 PT yang melakukan pelanggaran terhadap SN-Dikti. Adapun pelanggaran yang ditemukan antara lain kekurangan dosen, nisbah dosen, dan pelaporan pangakalan data Dikti sedangkan pada tahun 2018, LLDIKTI Wilayah XIV Papua dan Papua Barat melakukan kegiatan monitoring, pengawasan, pengendalian, pembinaan dan evaluasi kinerja akademik,

ISSN : 2301-7988

E-ISSN : 2581-0588

DOI $: 10.32736 /$ sisfokom.v8i2.672 
menemukan hampir 27 PT dengan permasalahan yang meluputi akreditasi institusi dan program studi, pelaporan PDPT, jabatan fungsional, sertifikasi dosen, beban kinerja dosen serta nisbah dosen.

Tim EKA yang dibentuk oleh Kopertis Wilayah XIV pada Tahun 2017 memiliki tugas dan peran untuk melakukan pemeriksaan dugaan pelanggaran PT yang bertujuan untuk membina Perguruan Tinggi Bermasalah (PTB), agar dapat sehat kembali dan dapat menjalankan Tri Dharma Perguruan Tinggi sesuai dengan SN-PT, menjamin masyarakat untuk mendapatkan pilihan PT yang sehat, sebagai tempat studi dan melindungi masyarakat dari malpraktek pendidikan tinggi yang tidak sehat, tidak legal, dan merugikan.

Kegiatan monitoring dan evaluasi terhadap kinerja akademik PT pada LLDIKTI Wilayah XIV dilakukan berdasarkan data dan informasi yang berasal dari laporan/pengaduan masyarakat secara lisan/tulisan, hasil pemantauan dan evaluasi, serta pemberitaan melalui media masa. LLDIKTI saat ini mengalami kesulitan dalam mendapatkan informasi atau keluhan dari masyarakat tentang pelanggaran PT dan juga kesulitan melakukan pemantauan terhadap penyelenggaraan PT adalah karena faktor geografis wilayah PT yang sangat luas dan jaringan transportasi yang sulit maupun terbatas serta tidak adanya sistem untuk menampung dan mengelolah keluhan atau pengaduan masyarakat terkait pelanggaraan-pelanggaran yang dilakukan oleh PT.

Pada prinsipnya pelayanan pengaduan masyarakat kepada pemerintah diupayakan agar mempermudah masyarakat yang akan menyampaikan pengaduannya, antara lain dengan menyediakan layanan hotline, faksimili dan situs web sebagai sarana mempermudah pengaduan masyarakat. Beberapa kebijakan nasional yang ditetapkan dan kebijakan lainnya yang telah ada akan disempurnakan antara lain adalah kebijakan di bidang pengaduan masyarakat [3].

Beberapa penelitian terkait tentang sistem informasi pengaduan antara lain penelitian yang berjudul "sistem informasi pengaduan layanan universitas", penelitian ini menghasilkan sebuah sistem informasi yang dapat menampung semua keluhan mengenai fasilitas dan pelayanan yang disediakan oleh universitas [8]. Penelitian lain dengan judul "Sistem Pengaduan Layanan Akademik Menggunakan Responsive Web Design" yang mengembangkan suatu sebuah aplikasi yang digunakan sebagai sistem monitoring kepuasan mahasiswa terhadap layanan akademik yang diberikan oleh BAAK, Keuangan dan Sarpras serta memberikan hak kepada mahasiswa untuk dapat menyampaikan keluhannya kepada pihak layanan akademik melalui media yang telah disediakan [9]. Penelitian lain terkait sistem informasi manajamen yang berjudul "Management Information System for Monitoring and Inspection of the Implementation of Universities", yang mengembangkan sistem informasi manajemen untuk pendataan pelanggaran $\mathrm{PT}$, penjadwalan dalam kegiatan pemerikasaan PT [2].

\section{METODE}

Dalam penelitian ini, alur pelaksanaan penelitian secara detail dapat dilihat pada Gambar 1. Sedangkan untuk perancangan SIM Pengaduan Masyarakat dan Monitoring Kinerja Akademik PT menggunakan metode pengembangan SDLC (System Development Life Cycle) Waterfall. Metode ini merupakan salah satu metode yang populer dalam pengembangan perangkat lunak yang menggambarkan pendekatan pengembangan yang sistematis dan berurutan (sekuensial) [4].

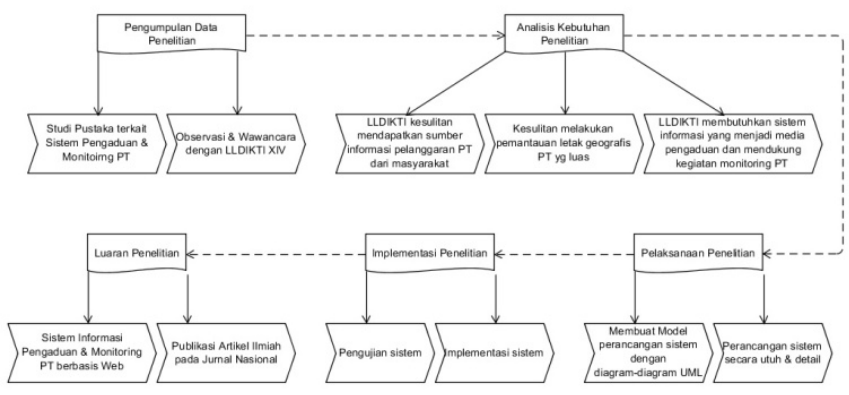

Gambar 1. Alur Pelaksanaan Penelitian

\section{A. Metode Pengembangan Sistem}

Perancangan Sistem Informasi Manajemen Pengaduan Masyarakat dan Monitoring Kinerja Akademik PT dalam penelitian ini menggunakan metode waterfall yang terdiri dari beberapa tahapan perancangan seperti terlihat pada Gambar 2. Tahapan pengembangan sistem menggunakan metode waterfall sangat terorganisir karena tahapan pengerjaan sistem dilakukan secara berurutan dan setiap tahapan/langkah saling berhubungan satu dengan yang lain, dimana setiap langkah harus diselesaikan sebelum pindah ke langka berikutnya sehingga kualitas perancangan sistem bergantung pada penyelesaian setiap tahapan pengerjaan yang harus dilakukan dengan baik.

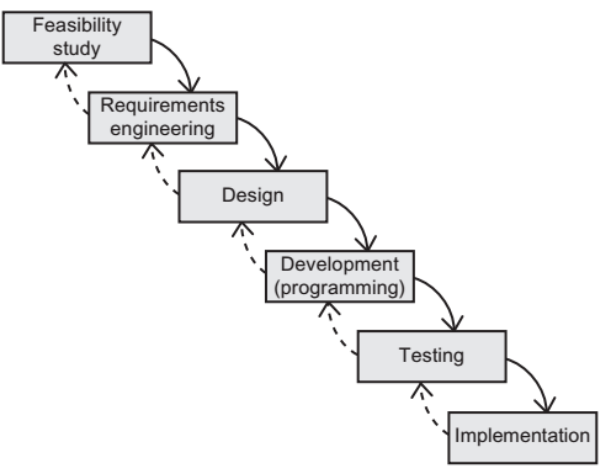

Gambar 2. Metode Waterfall [6]

Tahapan-tahapan dalam metode Waterfall adalah studi kelayakan (Feasibility study) yang merupakan tahapan awal yang harus diselesaikan sebelum tahapan rekayasa sistem dapat dimulai, dan rekayasa sistem harus diselesaikan sebelum

ISSN : :2301-7988

E-ISSN : 2581-0588

DOI $\quad: 10.32736 /$ sisfokom.v8i2.672 
tahapan desain dapat dimulai, dan seterusnya. Untuk melengkapi tahapan-tahapan dengan cara ini memastikan bahwa sistem yang dirancang dapat dipahami dengan baik melalui dokumentasi dan tinjauan dari setiap tahapan dan memastikan kualitas sistem menjadi lebih baik. Garis putusputus dan panah pada Gambar 2 menunjukkan hubungan atau relasi antara setiap tahapan dimana jika masalah terjadi pada salah satu tahapan, maka harus kembali ke tahapan sebelumnya untuk memperbaiki masalah tersebut [6].

Proses pengembangan sistem menggunakan metode waterfall memeliki beberapa tahapan anatar lain :

\section{- $\quad$ Feasibility study}

Sebelum pengembangan sistem dapat dimulai, diperlukan pendanaan. Studi kelayakan melibatkan investigasi awal dalam penelitian untuk mengevaluasi potensi keberhasilan untuk mendukung pengambilan keputusan. Kegiatan ini bertujuan agar peneliti atau pengembang sistem memahami secara obyektif sumber daya dan biaya yang dibutuhkan dalam penyelesaian pengembangan sistem.

\section{- $\quad$ Requirements engineering}

Tahap ini bertujuan untuk mendapatkan pemahaman tentang apa yang dibutuhkan oleh sistem yang akan dikembangkan melalui kajian pustaka terhadap sumbersumber yang berkaitan seperti buku dan jurnal ilmiah dan melakukan proses pengumpulan data yang dibutuhkan untuk perancangan sistem. Pada tahapan ini juga, dilakukan observasi dan analisis terhadap kebutuhan sistem, sehingga menghasilkan informasi atau dokumen serta pemahaman tentang prosedur sistem secara menyeluruh yang menjadi persyaratan dalam siklus pengembangan sistem. Persyaratan yang dihasilkan selama tahapan ini menjadi input untuk tahapan desain sistem.

- Design

Tahap desain dilakukan setelah semua persyaratan kebutuhan perancangan sistem terpenuhi. Tahap ini merupakan tahapan untuk mengimplementasi kebutuhan-kebutuhan pada tahap sebelumnya dengan membuat pemodelan arsitektur sistem yang rancang menggunakan diagram-diagram Unified Modeling Language (UML) meliputi diagram use case, activity dan diagram class. UML digunakan sebagai alat bantu untuk melakukan abstraksi terhadap sebuah perangkat lunak yang berbasis objek dan dapat mempermudah pengembangan perangkat lunak yang berkelanjutan karena setiap tahapan proses pengembangan sistem terdokumentasi. Hasil dari tahapan ini berupa dokumen yang digunakan oleh pengembang untuk pembuatan sistem atau perangkat lunak.

- Development (programming)

Tahapan ini bertujuan untuk menerjemahkan dokumen perancangan sistem pada tahap desain untuk membuat code program atau mengerjakan sistem yang dirancang. Tahap ini merupakan tahap implementasi dari tahap desain yang secara teknis akan dilakukan oleh pengembang atau programmer. Setelah selesai melakukan pengkodean atau pengerjaan sistem, tahap selanjutnya adalah melakukan pengujian terhadap sistem tersebut.

- $\quad$ Testing

Testing merupakan tahapan pengujian terhadap sistem yang dirancang. Hasil peracangan sistem sebelum diimplementasi, sistem harus melalui tahapan pengujian yang bertujuan untuk melakukan pengujian setiap fungsifungsi atau prosedur sistem untuk memastikan sistem berjalan dan berfungsi dengan baik.

- Implementation

Tahap ini adalah tahap final dalam perancangan sistem setalah melalui hasil analisa, desain, pengujian dan sampai pada implementasi untuk diserahkan ke pengguna dengan memastikan semua fungsi dan prosedur sistem berjalan dengan baik.

\section{HASIL DAN PEMBAHASAN}

\section{A. Analisa Sistem}

Kegiatan monitoring evaluasi kinerja akademik PT di LLDIKTI Wilayah XIV Papua dan Papua Barat saat ini merupakan kegiatan rutin setiap tahun yang bertujuan untuk pengendalian, pengawasan, dan pembinaan kepada PT. Tugas LLDIKTI adalah membantu peningkatan mutu penyelenggaraan Pendidikan Tinggi pada semua PT baik negeri maupun swasta agar dapat menyelenggarakan Pendidikan Tinggi secara akuntable yang sesuai dengan SN DIKTI. Dalam kegiatan monitoring LLDIKTI harus melakukan evaluasi sebelum melakukan kegiatan, mencakup identifikasi duagaan-dugaan pelanggaran yang dibuat oleh PT berdasarkan sumber data dan informasi yang berasal dari laporan/pengaduan masyarakat secara lisan/tulisan, hasil pemantauan, dan pemberitaan melalui media masa.

Kendala-kendala LLDIKTI saat ini adalah kesulitan dalam mendapatkan data atau informasi keluhan dari mayarakat terkait pelanggaran yang dibuat oleh PT dan kesulitan dalam melakukan pemantauan terhadap penyelenggaraan PT karena faktor geografis wilayah PT yang sangat luas dan transportasi yang terbatas. LLDIKTI membutuhkan sebuah sistem berbasis web karena dapat diakses kapan dan dimana saja. Sistem ini akan menjadi media untuk menampung pengaduan masyarakat terkait pelanggaran penyelenggaraan PT, pengaduan ini kemudian menjadi sumber data dalam melakukan kegiatan monitoring dan evaluasi kinerja akademik PT di wilayah Papua dan Papua Barat.

ISSN : :2301-7988

E-ISSN : 2581-0588

DOI : $10.32736 /$ sisfokom.v8i2.672 


\section{B. Diagram Use case}

Diagram use case sistem digunakan untuk mengilustrasikan kebutuhan (requirements) dari sistem yang menjelaskan secara visual konteks dari interaksi antara aktor dengan sistem. Setiap use case menyatakan spesifikasi perilaku (fungsionalitas) dari sistem yang sedang dijelaskan yang memang dibutuhkan oleh aktor untuk memenuhi tujuannya [2], [5]. Diagram use case merupakan pemodelan untuk kelakuan (behavior) sistem informasi yang akan dirancan. Untuk mendapatkan gambaran interkasi antara pengguna dan sistem pada SIM pengaduan masyarakat dan monitoring kinerja akademik PT maka dimodelkan dengan menggunakan diagram use case yang secara detail ditunjukan pada Gambar 3.

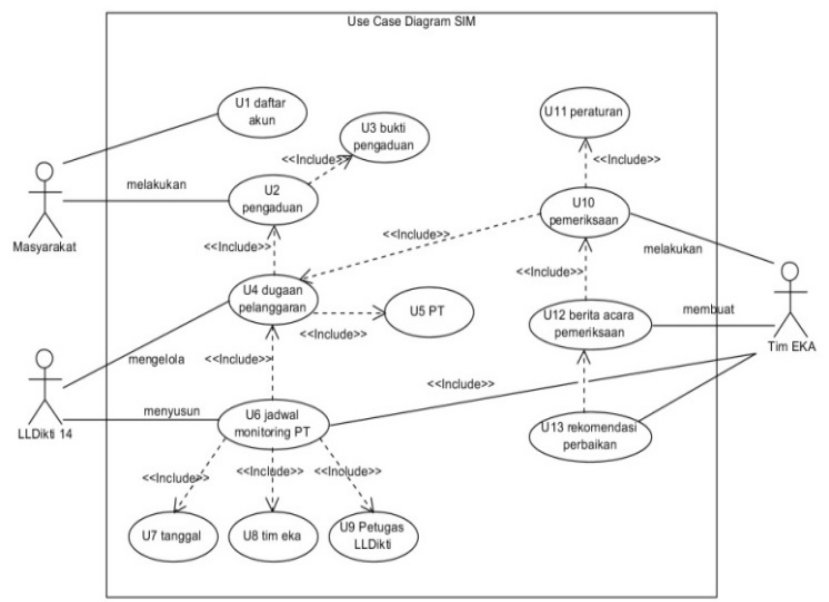

Gambar 3. Use case Diagram SIM Pengaduan dan Monitoring PT

\section{Diagram Activity}

Diagram activity adalah diagram yang menggambarkan konsep aliran data/kontrol atau aktivitas dari sebuah sistem. Diagram ini bersifat dinamis dalam pemodelan fungsi-fungsi dalam suatu sistem dan memberi tekanan pada aliran kendali antar objek [2].

Diagram activity dari SIM pengaduan masyarakat dan kegiatan monitoring evaluasi kinerja akademik PT terdiri dari diagram activity buat pengaduan, proses pengaduan oleh LLDIKTI dan penyusunan jadwal kegiatan monitoring PT yang ditunjukan pada Gambar 4, 5 dan 6 .

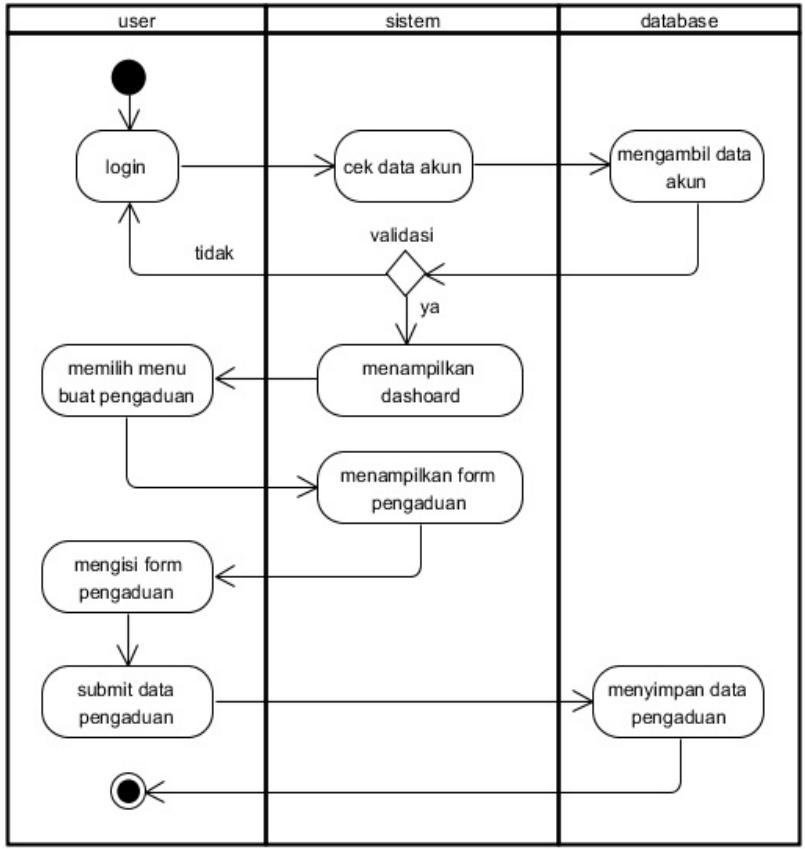

Gambar 4. Activity Diagram pembuatan Pengaduan

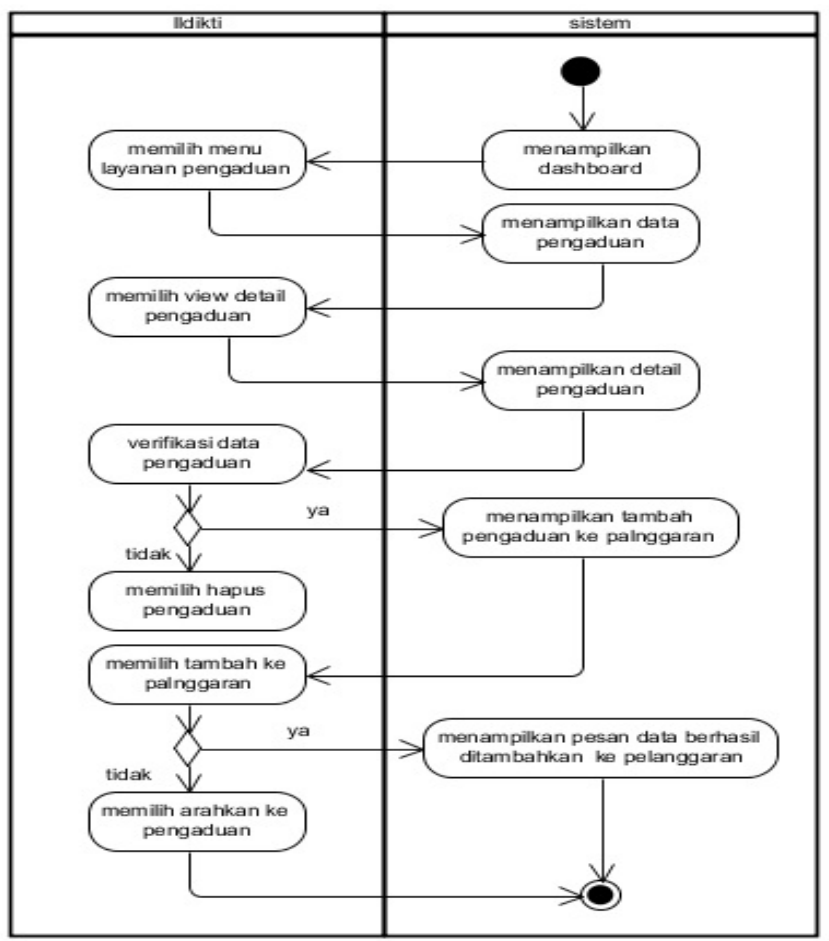

Gambar 5. Activity Diagram Manajemen Pengaduan

Gambar 4 : menjelaskan proses kirim pengaduan baru yang dilakukan oleh masyarakat (user). User sebelum membuat pengaduan harus melakukan login ke sistem terlebih dahulu, sistem akan mengecek ke database username dan 
password yang dimiliki apakah sesuai atau tidak, apabila sesuai, user berhasil login dan sistem akan menampilkan dashboard pengaduan. Untuk membuat pengaduan baru, user harus memilih menu buat pengaduan, kemudian sistem akan menampilkan form pengaduan dan user harus mengisi dengan memasukan judul pengaduan, kategori pengaduan, detail pengaduan, dan user dapat melampirkan data berupa dokumen atau foto pada form pengaduan. Setelah selesai mengisi form, user akan melakukan submit dan data pengaduan akan tersimpan pada database sistem.

Gambar 5 : menjelaskan manajemen data pengaduan dari masyarakat yang menjadi sumber data untuk melakukan kegiatan monitoring PT. Untuk mengelola data pengaduan dalam sistem, admin LLDIKTI harus melakukan login ke sistem, setelah berhasil sistem akan menampilkan dashbord dan admin kemudian memilih menu layanan pengaduan untuk melihat data pengaduan dari masyarakat. Untuk melakukan verifikasi data pengaduan, admin harus memilih detail pengaduan untuk melihat secara lengkap data pengaduan dan apabila data tersebut valid maka akan ditambahkan ke data pelanggaran PT, jika data tidak valid maka admin bisa lansung menghapus data pengaduan tersebut.

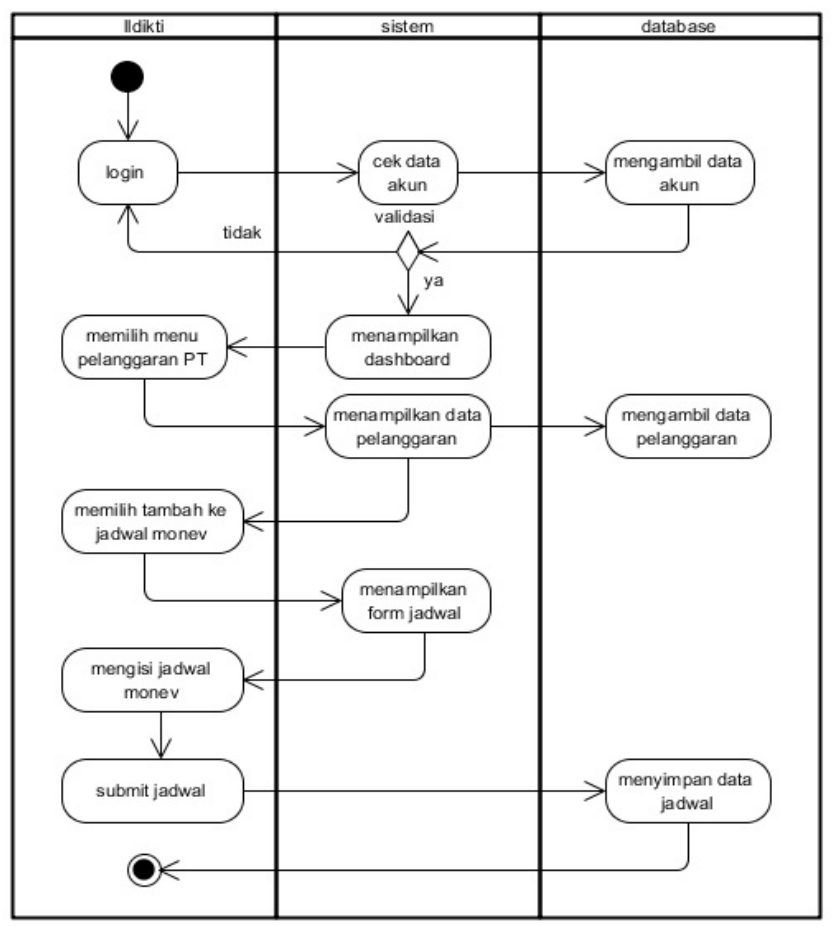

Gambar 6. Activity Diagram Penyusunan Jadwal

Gambar 6 : menjelaskan proses penyusunan jadwal kegiatan monitoring evaluasi kinerja akademik PT. Proses ini dimulai dengan admin LLDIKTI harus melakukan login ke sistem dan setelah berhasil, admin akan memilih menu pelanggaran PT untuk melihat data pelanggaran PT secara lengkap. Untuk membuat jadwal kegiatan, berdasarkan data pelanggaran PT dari sumber data pengaduan masyarakat, admin akan memilih pelanggaran dan menambahkan ke jadwal kegiatan, sistem akan menampilkan secara otomatis data pelanggaran PT yang dipilih pada form jadwal dan admin akan melengkapi form dengan mengisi dan memilih pegawai LLDIKTI yang ditugaskan untuk mengikuti kegiatan, memilih Tim Evaluasi Kinerja Akademik, tanggal kegiatan serta daerah kegiatan monev PT. Setelah mengisi form jadwal dengan lengkap, admin akan melakukan submit dan data jadwal tersimpan dalam database.

\section{Model Data Konseptual}

Model data konseptual merupakan sebuah model data yang digunakan untuk mendefinisikan tingkat abstraksi data, relasi entitas atau konsep yang merepresentasikan data dari domain masalah. Model ini menggambarkan rincian karakteristik entitas (seperti atribut, tipe data dan kunci utama) [2], [7]. Model data SIM pengaduan masyarakat dan monitoring evaluasi kinerja akademik PT dapat dilihat pada Gambar 6.

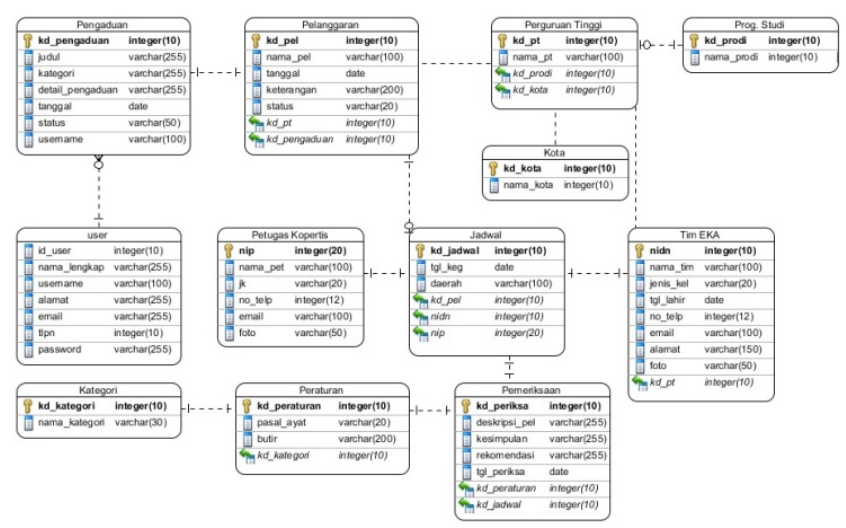

Gambar 7. Model Data SIM Pengaduan \& Monitoring PT

\section{E. Implementasi Sistem}

Tahap implementasi sistem merupakan tahap dimana sistem yang dikembangkan sesuai dengan hasil tahap perancangan mengikuti metode waterfall. Hasil dari sistem yang dikembangkan akan ditunjukkan melalui screenshot dari sistem itu sendiri. Berikut adalah hasil dari implementasi sistem yang telah dibangun.

ISSN : :2301-7988

E-ISSN : 2581-0588

DOI $\quad: 10.32736 /$ sisfokom.v8i2.672 


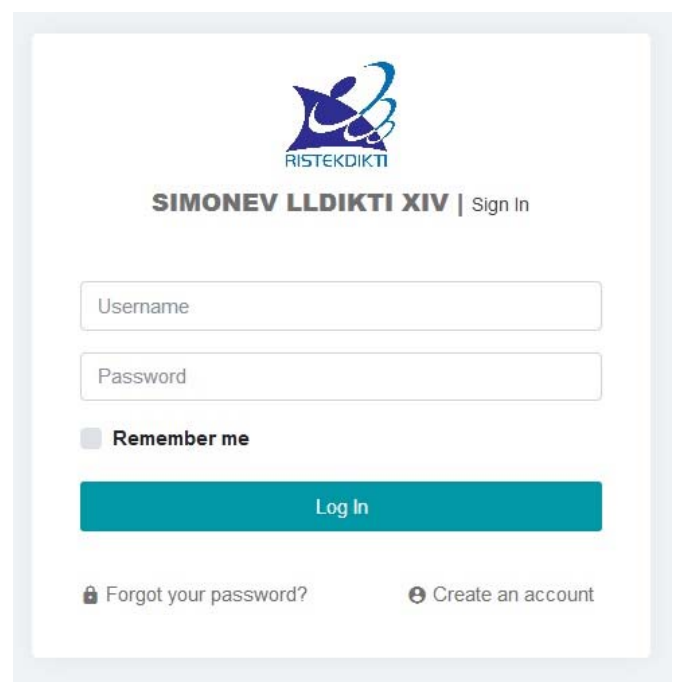

Gambar 8. Halaman login sistem

Gambar 8. Menunjukan tampilan login untuk pengguna pada SIM pengaduan masyarakat dan monitoring kinerja akademik PT. Proses login pada sistem dilakukan dengan memasukan username dan password, apabila berhasil maka sistem menampilkan halaman dashboard dari pengguna yang melakukan login. Dalam sistem ini terdapat tiga pengguna antara lain masyarakat sebagai user yang membuat pengaduan, admin LLDIKTI sebagai pengelola pengaduan dan kegiatan monitoring PT serta Tim EKA yang merupakan tim pemeriksa PT yang dibentuk oleh LLDDIKTI. Tampilan halaman dashboard dan form pengaduan untuk user membuat pengaduan baru dapat dilihat pada Gambar 8 .

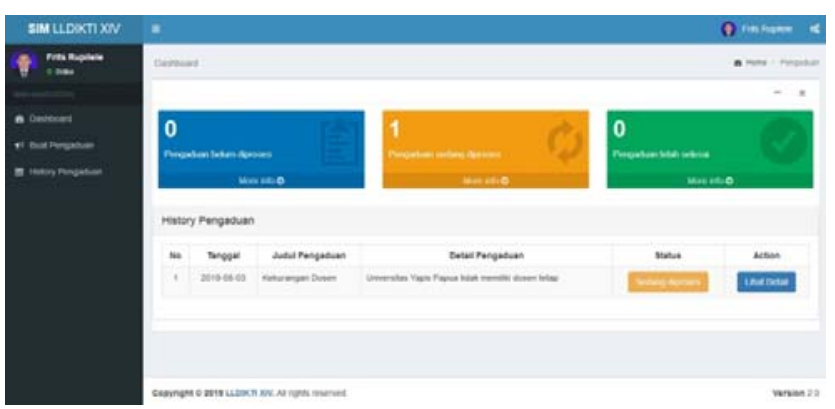

Gambar 9. Dashboard User

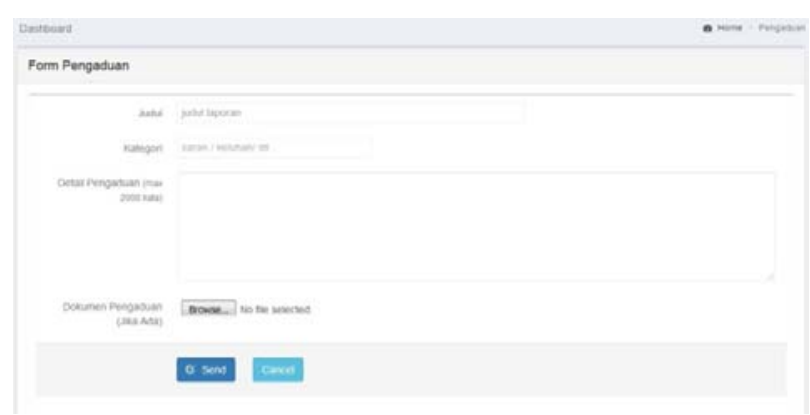

Gambar 10. Form Pengaduan
Gambar 10. menjelaskan proses pembuatan pengaduan baru oleh user. Untuk membuat pengaduan, user akan memilih menu buat pengaduan sehingga tampil form pengaduan dan user harus mengisi form yang berisi judul pengaduan, kategori pengaduan, detail pengaduan, serta user dapat melampirkan dokumen sebagai bukti pengaduan pada form kemudian user melakukan submit maka data pengaduan akan tersimpan dalam sistem. Data pengaduan yang kirim, akan dilihat oleh LLDIKTI saat admin melakukan login ke sistem, yang akan menampilkan halaman dashboard admin LLDIKTI yang terlihat pada Gambar 11 .

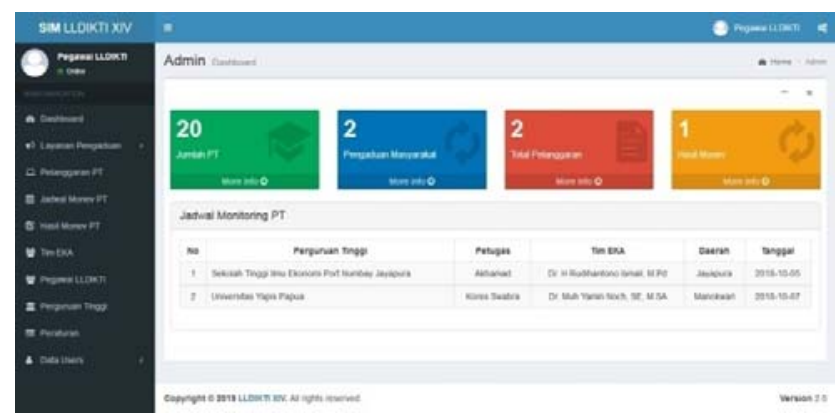

Gambar 11. Dashboard Admin LLDIKTI

Gambar 11. Menampilkan halaman admin LLDIKTI yang bertugas mengelolah data SIM pengaduan dan monitoring kinerja akademik PT yang meliputi data pengaduan masyarakat, data pelanggaran PT, jadwal kegiatan monev, hasil monev, data Tim EKA dan Pegawai LLDIKTI. Untuk data pengaduan masyarakat, admin LLDIKTI akan melakukan verifikasi data yang masuk, jika data tersebut valid maka akan ditambahkan menjadi data pelanggaran PT sebagai sumber data dalam kegiatan monitoring PT. Data pelanggaran PT dapat dilihat pada Gambar 12.

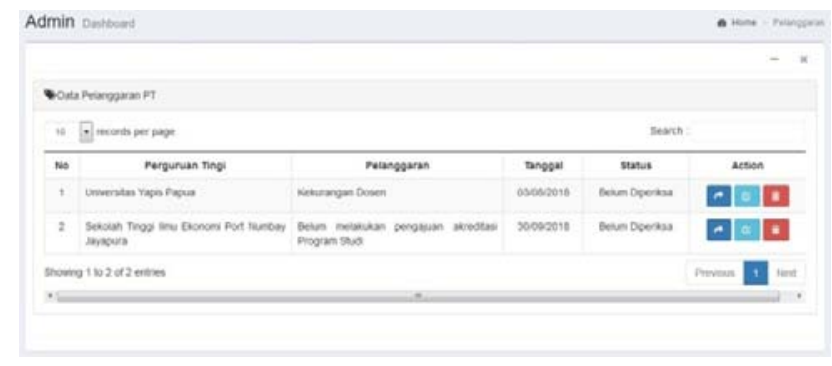

Gambar 12. Data Pelanggaran PT

Berdasarkan data pelanggaran, admin LLDIKTI akan menyusun jadwal kegiatan monitoring PT dengan mengisi form jadwal yang meliputi data perguruan tinggi dan pelanggaran yang secara otomatis terisi di form, data petugas LLDIKTI, Tim EKA, tanggal kegiatan, daerah atau tempat kegiatan monitoring. Jadwal yang telah disusun oleh LLDIKTI dapat dilihat oleh Tim EKA pada halaman dashboardnya yang dapat dilihat pada Gambar 13, sehingga Tim yang ditugaskan dapat mengetahui PT dan daerah tempat kegiatan monitoring. 


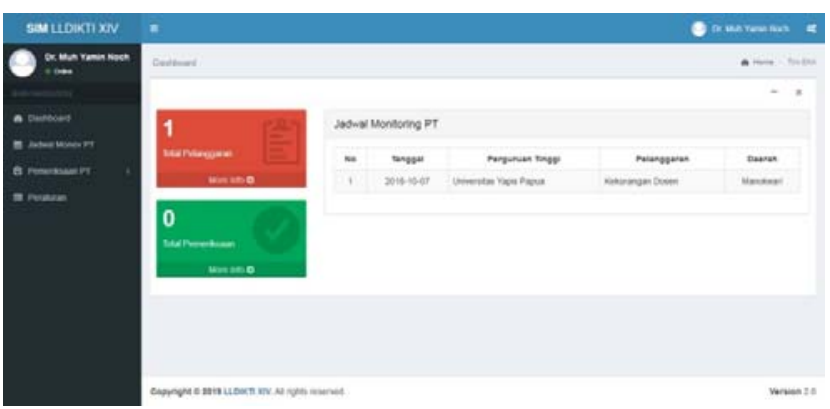

Gambar 13. Dashboard Tim EKA

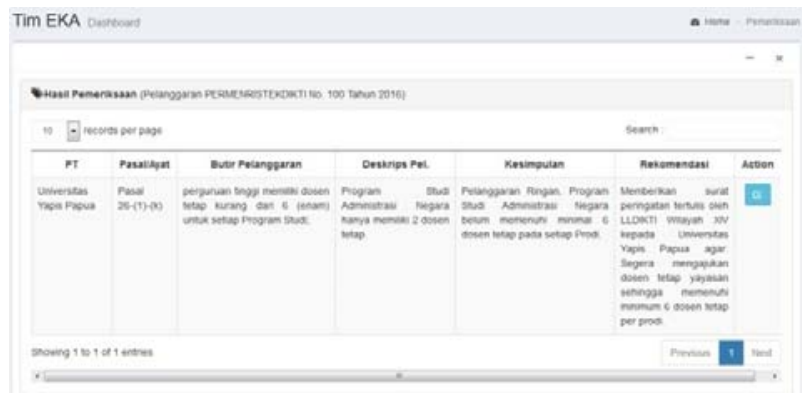

Gambar 14. Hasil Pemeriksaan Tim EKA

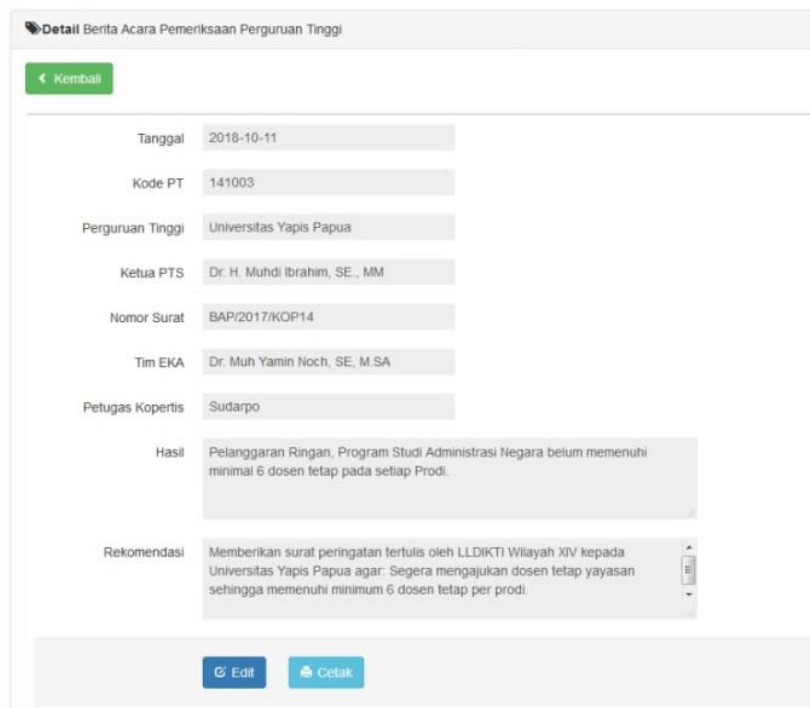

Gambar 15. Berita Acara Pemeriksaan PT

Gambar 13, menunjukan dashboard Tim EKA yang berisi jadwal monitoring PT, data total pelanggaran, data peraturan yang berisi pasal, ayat dan butir pelanggaran berdasarkan Permenristekdikti Nomor 100 Tahun 2016 dan data pemeriksaan PT meliputi berita acara pemeriksaan dan hasil pemeriksaan.
Proses pemeriksaan yang dilakukan oleh Tim EKA yaitu dengan memilih data PT untuk diperiksa pada jadwal yang secara otomatis sistem akan menampilkan form pendataan pemeriksaan yang berisi pelanggaran yang dibuat oleh PT, pasal, ayat, dan butir pelanggaran dipilih berdasarkan peraturan, deskirpsi pelanggaran, kesimpulan, dan rekomendasi kepada LLDIKTI terhadap pelanggaran yang dibuat oleh PT dan kemudian data disubmit dan akan tampil pada menu hasil pemeriksaan yang ditunjukan pada Gambar 14, dan berita acara pemeriksaan PT pada Gambar 15.

\section{KESIMPULAN}

Hasil analisa dan pembahasan dalam pengembangan SIM pengaduan masyarakat dan monitoring kinerja akademik PT dapat disimpulkan bahwa permasalahan pada LLDIKTI Wilayah XIV Papua dan Papua Barat dalam mendapatkan informasi atau keluahan dari masyarakat tentang pelanggaran PT, manajemen pendataan pelanggaran, manajemen kegitaan monitoring PT sampai pada pemeriksaan penyelenggaraan PT yang meliputi penjadwalan, penyiapan dokumen, penyampaian informasi sampai dengan laporan pemeriksaan PT masih dijalankan secara manual. Sistem Informasi yang dibangun dalam penelitian ini berbasis web, sehingga menjadi solusi permasalahan letak geografis PT yang tersebar pada daerah-daerah kepulauan dan menghasilkan sistem yang menyediakan media pengaduan masyarakat sehingga membantu LLDIKTI dalam manajemen pendataan pelanggaran PT dan manajemen kegiatan monitoring kinerja akademik PT yang terintegrasi dan terpusat, dan menghasilkan laporan data pemeriksaan PT yang menjadi masukan dan informasi bagi LLDIKTI dan kementerian dalam pemetaan kualitas kelembagaan Pendidikan tinggi.

\section{DAFTAR PUSTAKA}

[1] A. S. Syamsul Bachri Thalib, Abdullah Sinring, "Evaluasi Kinerja Akademik Fakultas Ilmu Pendidikan Universitas Negeri Makassar," vol. 1, no. 1, 2018.

[2] F. G. J. Rupilele, I. Soulisa, A. Palilu, A. Hasibuan, O. F. Winesty, F. A. Goraph, H. Sidete, E. Mouw, S. Laritmas, and S. Tondo, "Management Information System for Monitoring and Inspection of the Implementation of Universities," vol. 7, pp. 451-456, 2018.

[3] W. J. Shudiq, "Desain Program Sistem Informasi Pengaduan Masyarakat Pada Kecamatan Kademangan Terintegrasi SMS Gateway," pp. 1-6, 2017.

[4] R. S. Pressman and B. R. Maxim, Software Engineering A Practitioner's Approach, Eighth Edi. New York: McGraw-Hill Education, 2015.

[5] T. A. Kurniawan, "Pemodelan Use Case ( UML ): Evaluasi Terhadap Beberapa Kesalahan Dalam Praktik Use Case ( UML ) Modeling: Evaluation On Some Pitfalls In Practices," vol. 5, no. 1, pp. 77-86, 2018.

[6] James Cadle (editor), "Developing Information Systems Practical guidance for IT professionals", BCS Learning \& Development Ltd, a wholly owned subsidiary of BCS The Chartered Institute for IT, Swindon, UK, 2014.

[7] R. A, Silva, and Rodrigues, "Data Modeling and Data Analytics: A Survey from a Big Data Perspective", Journal of Software Engineering and Applications., vol. 8, no. 12, pp. 617-634, 2015. 
[8] G. Nalendro, "Sistem Informasi Pengaduan Layanan Universitas", Program Studi Teknik Informatika, Fakultas Teknologi Industri Universitas Islam Indonesia, 2019.

[9] Y. I. Melani, "Sistem Pengaduan Layanan Akademik Menggunakan Responsive Web Design" Jurnal SISFOKOM, vol. 08, no. 01, pp. 39-45, 2019

$: 2301-7988$

E-ISSN : 2581-0588

DOI $: 10.32736 /$ sisfokom.v8i2.672 